\title{
Norcantharidin reverses cisplatin resistance and inhibits the epithelial mesenchymal transition of human non-small lung cancer cells by regulating the YAP pathway
}

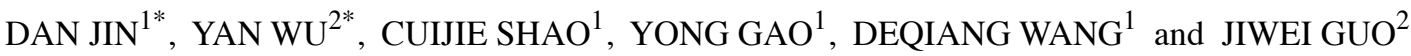 \\ ${ }^{1}$ Department of Pain Medicine, and ${ }^{2}$ Cancer Research Institute, Binzhou Medical University Hospital, \\ Binzhou, Shandong 256603, P.R. China
}

Received December 5, 2017; Accepted May 25, 2018

DOI: $10.3892 / o r .2018 .6486$

\begin{abstract}
Non-small cell lung cancer (NSCLC) accounts for $>80 \%$ of all lung cancer cases, which are the leading cause of cancer-related mortality worldwide. The clinical efficacy of available therapies for NSCLC is often limited due to the development of resistance to anticancer drugs, particularly to cisplatin (DDP). Norcantharidin (NCTD) is a traditional Chinese medicine used in the treatment of many types of cancer, to which patients do not develop resistance. The aim of the present study was to examine the potential synergistic effects of NCTD and DPP on the viability of the the DDP-resistant NSCLC cell line, A549/DDP. We further explored the potential underlying mechanisms by examining the expression of the oncogene, Yes-associated protein 1 (YAP), whose activation was recently found to be associated with drug resistance. We further examined a series of human lung cancer cell lines and tissues from patients with lung cancer, which revealed that YAP activation contributed to lung cancer initiation, progression and metastasis, and was associated with a poor prognosis, and confering resistance against targeted therapies. Moreover, YAP expression was evaluated in the A549/DDP cells treated with NCTD, DDP, or both drugs. The combined treatment significantly sensitized the A549/DDP cells to DDP-induced growth inhibition by reducing YAP promoter activity (based on transcriptional expression) and the expression of its target
\end{abstract}

Correspondence to: Dr Deqiang Wang, Department of Pain Medicine, Binzhou Medical University Hospital, No. 661, Huanghe 2nd Road, Binzhou, Shandong 256603, P.R. China

E-mail: wangdeqiangbyfy@163.com

Dr Jiwei Guo, Cancer Research Institute, Binzhou Medical University Hospital, No. 661, Huanghe 2nd Road, Binzhou, Shandong 256603, P.R. China

E-mail: guojiwei0510@163.com

*Contributed equally

Key words: non-small cell lung cancer, YAP, norcantharidin, cisplatin, epithelial-to-mesenchymal transition, cisplatin resistance genes, connective tissue growth factor $(C T G F)$ and cysteine rich angiogenic inducer 61 (CYR61). Furthermore, compared to the individual treatments, combined treatment increased cell apoptosis and senescence, and decreased epithelial-to-mesenchymal transition and the cell migratory and invasive ability. On the whole, our data indicate that the application of NCTD with reverses DDR resistance and thus, this combined treatment may have promising prospects for use in improving the outcome of patients with NSCLC.

\section{Introduction}

Lung cancer, a malignancy with a high incidence, is the leading cause of cancer-associated death worldwide (1). Lung cancer tumorigenesis and development are the outcome of the synergistic effects of multifactorial processes. Based on the histological type, lung cancer can be classified into small cell lung cancer and non-small cell lung cancer (NSCLC), with NSCLC accounting for $>80 \%$ of all lung cancer cases (2). Approximately $75 \%$ of patients with NSCLC are diagnosed at a late stage, when the cancer has already metastasized to distant organs, and thus, NSCLC is associated with a relatively low overall 5-year survival rate $(3,4)$, and remains the most intractable malignancy. There is thus an urgent need to develop novel therapeutic strategies for patients with NSCLC.

Cisplatin (DDP)-based therapy has long been the primary chemotherapeutic agent used in clinical trials of NSCLC treatment $(5,6)$. DDP is a non-specific, cell cycle-targeting antitumor drug that binds to the DNA of NSCLC cells and induces irreparable lesions, inducing apoptosis (7). However, the clinical efficacy of DDP is often limited by the development of resistance following prolonged therapy, which is considered a primary reason for therapeutic failure (8-10). Thus, it is important to explore useful methods with which to reverse DDP resistance, in order to improve the outcome of patients with NSCLC.

Accumulating evidence suggests the involvement of the Yes-associated protein (YAP) pathway in NSCLC initiation, progression and metastasis (11-13). The YAP pathway, which involves a kinase cascade, plays a critical role in governing organ size and tumorigenesis by simultaneously regulating cell proliferation and apoptosis (14-16). The core components 
of the YAP pathway are the kinases, mammalian Ste20-like kinase (MST) and large tumor suppressor (LATS), the adaptor proteins Salvador (SAV) and MOB, and the YAP-TEA domain transcription factor (TEAD) transcriptional complex. MST forms a complex with its regulatory protein SAV, then phosphorylates and activates LATS, which in turn phosphorylates YAP (17-19). Phosphorylated YAP (p-YAP) is then retained in the cytoplasm, where it interacts with 14-3-3 proteins and is degraded. By contrast, unphosphorylated YAP is translocated from the cytoplasm to the nucleus, where it binds to the transcription factor, TEAD, and regulates the expression of downstream target genes (20). The aberrant activation of YAP has been shown to increase cell proliferation and inhibit apoptosis, thereby contributing to tumor overgrowth. However, to the best of our knowledge, few studies to date have investigated the association between YAP and DDP resistance in NSCLC.

The resistance and high toxicity of anticancer drugs remain an impassable barrier for cancer therapy. Combining drugs is an effective strategy which may be used to overcome these issues. Norcantharidin (NCTD) is a demethylated form of cantharidin, a Chinese traditional medicine isolated from the blister beetle (21) and has long been used in the treatment of patients with urinary bladder carcinoma and gallbladder cancer in China $(22,23)$. Importantly, and at least to the best of our knolwege, no resistance to NCTD has been reported to date, demonstrating that it may be a good candidate for combination therapy with DDP. However, the effects of NCTD on DDP resistance have not yet been investigated.

Thus, we hypothesized that NCTD may exert synergistic effects in combination with DDP, improving the viability, proliferation, morphology and DDP sensitivity of NSCLC cells. This hypothesis was examined using the DDP-resistant NSCLC cell line, A549/DDP, and the underlying mechanism through which NCTD affects DDP sensitivity were explored by examining the expression of YAP and associated pathway components, the apoptosis and senescence rates, as well as invasion and epithelial-mesenchymal transition (EMT) ability following combined and individual treatments. These findings provide a foundation for NCTD/DDP combination treatment as a novel treatment strategy for NSCLC

\section{Materials and methods}

Cell lines and culture. The human NSCLC cell lines, A549, H1299, Calu6 and H520m and the human lung normal control cell line, HBEC-3KT (HBEC), were purchased from the American Type Culture Collection (ATCC, Manassas, VA, USA). The sub-line, 95-D (Cat. TCHu 61), was purchased from the Shanghai Institute of Biochemistry and Cell Biology, Chinese Academy of Sciences (Shanghai, China). The cells were cultivated in RPMI-1640 medium supplemented with 10\% FBS (HyClone, Logan, UT, USA), penicillin/streptomycin $(100 \mathrm{mg} / \mathrm{ml})$. Culture flasks were kept at $37^{\circ} \mathrm{C}$ in a humid incubator with $5 \% \mathrm{CO}_{2}$. The cisplatin resistant sub-line, A549/DDP, was a gift from the Resistant Cancer Cell Line (RCCL) collection (http://www.kent. ac.uk/stms/cmp/RCCL/RCCLabout.html). Another cisplatin resistant sub-line, H1299/DDP, had been established in our laboratory in 2016 by adapting the growth of H1299 cells in the presence of increasing concentrations of cisplatin until a final concentration of $12 \mu \mathrm{g} / \mathrm{ml}$, followed by cultivation in RPMI-1640 medium supplemented with 10\% FBS additionally contained $2 \mu \mathrm{g} / \mathrm{ml}$ cisplatin (24).

Plasmid constructs for overexpression. cDNA overexpressing constructs for Myc-tagged YAP were created from the pcDNA3.1 vector (Invitrogen, Carlsbad, CA, USA). To construct the core region of the YAP promoter, the region $-354 /+115$ of YAP was amplified by PCR from the pGL3-1536 and was inserted into the upstream of the pGL3-Basic vector (Promega Corporation, Madison, WI, USA) to generate the plasmid, YAPluc. The plasmid construct $(2 \mu \mathrm{g})$ was transfected into cells using Lipofectamine 2000 (Invitrogen).

Knockdown of Yap. siYAR1 $(1 \mu \mathrm{g})$, siYAP2 $(1 \mu \mathrm{g})$ or sicontrol $(1 \mu \mathrm{g})$ were transfected into the cells using Lipofectamine 2000 (cat. no. 11668019, Invitrogen) for the knockdown of YAP, followed by analysis $48-72 \mathrm{~h}$ later. The selected siRNA sequences were as follows: siYAP-1, 5'-AAGGUGAUACUA UCAACCAAAdTdT-3'; SIYAP-2, 5'-AAGACAUCUUCU GGUCAGAGAdTdT-3; and sicontrol, 5'-AAUUCUCCG AACGUGUCACGUdTdT-3'. These selected sequences were purchased from GenePharma (Shanghai, China).

$R N A$ isolation and $R T-q P C R$. Total RNA was isolated from the human lung normal HBEC cells and the cancer cells was isolated using TRIzol reagent (TransGen Biotech, Beijing, China) and retro-transcribed into first-strand cDNA using the TransScript All-in-One First-Strand cDNA Synthesis kjt (TransGen Biotech). The cDNA was subjected to reverse transcription PCR (RT-PCR) assay using corresponding primers. GAPDH (human) served as an internal control. The amplification for RT-PCR was performed as follows: a denaturation step at $94^{\circ} \mathrm{C}$ for $5 \mathrm{~min}$, followed by 30 cycles of amplification at $94^{\circ} \mathrm{C}$ for $30 \mathrm{sec}, 56^{\circ} \mathrm{C}$ for $30 \mathrm{sec}$ and $72^{\circ} \mathrm{C}$ for $30 \mathrm{sec}$. The reaction was terminated at $72^{\circ} \mathrm{C}$ for $10 \mathrm{~min}$ and the product of PCR was kept at $4^{\circ} \mathrm{C}$. The amplification for quantitative PCR (qPCR) was performed as follows: $1 \mu \mathrm{l}$ cDNA templates was subjected to RT-qPCR and the final RT-qPCR reaction mix contained $10 \mu \mathrm{l}$ Fast $\mathrm{SYBR}^{\mathrm{TM}}$-Green Master Mix (Thermo, Cat. 4385610). $0.5 \mu \mathrm{l}$ of each primer and $8 \mu \mathrm{l}$ RNase-free $\mathrm{H}_{2} \mathrm{O}$. The parameters for RT-qPCR were follows: A denaturation step at $94^{\circ} \mathrm{C}$ for $5 \mathrm{~min}$, followed by 40 cycles of amplification at $94^{\circ} \mathrm{C}$ for $20 \mathrm{sec}, 58^{\circ} \mathrm{C}$ for $20 \mathrm{sec}$ and $72^{\circ} \mathrm{C}$ for $20 \mathrm{sec}$. The reaction was termindated at $25^{\circ} \mathrm{C}$ for $5 \mathrm{~min}$. The relative expression levels were detected and analyzed by ABI 9600 (Applied Biosystems., USA) based on the formula of $2^{-\Delta \Delta c q}$ (25). The PCR primer sequences of RT-PCR and RT-qPCR were as follows: YAP forward, 5'-GGACCCCAG ACGACTTCCTCAACAG-3' and reverse, 5'-CCTTCCAGT GTGCCAAGGTCCACAT-3'; $C T G F$ forward, 5'-AATGCT GCGAGGAGTGGGT-3' and reverse, 5'-CGGCTCTAATCA TAGTTGGGTCT-3'; CYR61 forward, 5'-GAGTGGGTC TGTGACGAGGAT-3' and reverse, 5'-GGTTGTATAGGA TGCGAGGCT-3'; E-cadherin forward, 5'-ACCATTAAC AGGAACACAGG-3' and reverse, 5'-CAGTCACTTTCA GTGTGGTG-3'; vimentin forward, 5'-CGCCAACTACAT CGACAAGGTGC-3' and reverse, 5'-CTGGTCCACCTG CCGGCGCAG-3'; GAPDH forward, 5'-CTCCTCCTGTTC 
GACAGTCAGC-3' and reverse, 5'-CCCAATACGACCAAA TCCGTT-3'.

3-(4,5-Dimethylthiazol-2-yl)-2,5-diphenyltetrazolium bromide (MTT) assay. The cells at the log growth phase were seeded in a 96-well plate. Following overnight growth, the cells were treated with NCTD (8 or $16 \mu \mathrm{g} / \mathrm{ml})$, DDP $(6$ or $12 \mu \mathrm{g} / \mathrm{ml})$ or co-treatment with NCTD $(8 \mu \mathrm{g} / \mathrm{ml})$ and DDP $(6 \mu \mathrm{g} / \mathrm{ml})$ then incubated for $24,48,60,72$ and $96 \mathrm{~h}$. A total of $10 \mu \mathrm{l}$ of $5 \mathrm{mg} / \mathrm{ml}$ MTT (Sigma-Aldrich, St. Louis, MO, USA) was added followed by incubation for $4 \mathrm{~h}$. The absorbance was measured using a microplate reader (Infinite ${ }^{\circledR}$ F50; Tecan Group Ltd., Männedorf, Switzerland) at a wavelength of $570 \mathrm{~nm}$.

CCK-8 assay. For CCK-8 assay, $100 \mu 1$ of cell suspension (5,000 cells/ well) were dispenses in a $96-$ well plate. The plate was pre-incubated for $24 \mathrm{~h}$ in a humidified incubator at $37^{\circ} \mathrm{C}$, $5 \% \mathrm{CO}_{2}$. This was followed by the addition of NCTD $(2 \mu \mathrm{g} / \mathrm{ml}$ up to $16 \mu \mathrm{g} / \mathrm{ml})$, DDP ( $2 \mu \mathrm{g} / \mathrm{ml}$ up to $12 \mu \mathrm{g} / \mathrm{ml})$ or co-treatment with NCTD $(8 \mu \mathrm{g} / \mathrm{ml})$ and DDP $(6 \mu \mathrm{g} / \mathrm{ml})$ to the test plate for $60 \mathrm{~h}$. The plate was incubated for $72 \mathrm{~h}$ in the incubator. Subsequently, $10 \mu 1$ of CCK-8 (C0037; Beyotime, Shanghai, China) solution were added to each well of the plate followed by incubation at $37^{\circ} \mathrm{C}$ for $4 \mathrm{~h}$ in the incubator. The absorbance was measured at $450 \mathrm{~nm}$ using a microplate reader (Infinite ${ }^{\circledR}$ F50; Tecan Group Ltd., Männedorf, Switzerland).

Western blot analysis. The cells were washed with PBS and lysed with NP40 lysis buffer (10 mM Tris pH 7.4, $150 \mathrm{mM}$ $\mathrm{NaCl}, 1 \%$ Triton X-100, 1 mM EGTA pH 8.0, 1 mM EDTA $\mathrm{pH}$ 8.0, 0.5\% NP-40 and $1 \mathrm{mM}$ PMSF) supplied with Complete Protease Inhibitor Cocktail (cat. no. 04693116001, Roche, Germany). The protein concentration was measured with a colorimetric BCA Protein Assay kit (Pierce, Rockford, II USA). A total of $30 \mu \mathrm{g}$ protein were separated by SDS-PAGE, which was performed with $12 \%$ separating gels and transferred onto PVDF membranes. The membranes were blocked with $5 \%$ non-fat milk in TBST and incubated with the following primary antibodies: YAP $(1 \cdot 1,000$, sc-101199), Tubulin (1:1,000, sc-73242), LaminB (1:1,000, sc-133241), Myc (1:1,000, sc-40), Cyr61 (1:1,000, sc-374129), CTGF (1.1,000, sc-101586), E-cadherin (1:1,000, sc-71009), vimentin $(1: 1,000, \mathrm{sc}-66002)$ (all form Santa Cruz Biotechnology, Santa Cruz, CA, USA), p-YAP (1:1,000, ab56701) and active caspase-3 (1:1,000, ab2302) (both from Abcam, Cambridge, UK) overnight followed by incubation with HRP-conjugated secondary antibodies (1:5,000; ab6728; Abcam, Abcam Trading Company Ltd.,UK). Immunoreactive proteins were visualized using SuperSignal West Femto Chemiluminescent Substrate (Thermo Fisher Scientific, Inc., Waltham, MA, USA). The data were then analyzed using Image-Pro Plus 6.0 (Media Cybernetics, Inc.) and Tubulin and LaminB were used as internal controls.

Wound healing assay. The cells grown to confluence in 12 -well plates were treated with NCTD $(8 \mu \mathrm{g} / \mathrm{ml})$, DDP $(6 \mu \mathrm{g} / \mathrm{ml})$ or by co-treatment with NCTD $(8 \mu \mathrm{g} / \mathrm{ml})$ and DDP $(6 \mu \mathrm{g} / \mathrm{ml})$ for $48 \mathrm{~h}$ before a linear wound was created across the cell monolayer. Images were captured at the time points of 0 and $36 \mathrm{~h}$ after wounding. The relative distance of the scratches was observed under an optical microscope
(IX53, Olympus, Tokyo, Japan) and assessed using the ImageJ software.

Transwell assay. The cells were seeded on the upper chambers (with $8-\mu \mathrm{m}$ pore size Transwell inserts (Corning, New York, NY, USA) coated with Matrigel ${ }^{\mathrm{TM}}$ (cat. no. 356234; BD Biosciences, San Jose, CA, USA) in $300 \mu 1$ serum-free medium. Subsequently, 10\% FBS RPMI-1640 was added to the lower chamber. Following culture for $48 \mathrm{~h}$, the cells on the upper surface were removed using cotton swabs and these chambers were fixed in $4 \%$ paraformaldehyde and then stained with $0.1 \%$ crystal violet solution (cat. no. E607309; Sangon Biotech Co., Ltd., Shanghai, China) at $25^{\circ} \mathrm{C}$ for $20 \mathrm{~min}$. The cells were counted in 5 random fields per filter under a microscope (IX53; Olympus).

Immunofluorescence staining. For the analysis of the protein levels of YAP and Annexin V, the A549/DDP cells were grown on coverslips in a 24-well plate overnight and after $24 \mathrm{~h}$, they were treated with NCTD $(8 \mu \mathrm{g} / \mathrm{ml})$, DDP $(6 \mu \mathrm{g} / \mathrm{ml})$ or co-treated of NCTD $(8 \mu \mathrm{g} / \mathrm{ml})$ and DDP $(6 \mu \mathrm{g} / \mathrm{ml})$. After $48 \mathrm{~h}$, the cells were fixed in $4 \%$ formaldehyde for $30 \mathrm{~min}$ and blocked in 3\% BSA in PBS for $30 \mathrm{~min}$. The coverslips yere subsequently incubated with rabbit anti-YAP (\#8418; Cell Signaling Technology, Danvers, MA, USA), anti-CYR61 (24448; Abcam, Cambridge, MA, USA), anti-CTGF (6992; Abcam) and anti-Annexin V (sc-32321; Santa Cruz Biotechnology) monoclonal antibodies at a 1:1,000 dilution in PBS containing 3\% BSA. Alex Fluor AF 488 (green, 1:500, A-11029, Invitrogen, Carlsbad, CA, USA) and 594 (red, 1:500, A-11032; Invitrogen) anti-rabbit monoclonal secondary fluorescence antibodies at a 1:1,000 dilution in PBS containing 3\% BSA. In addition, $3 \mu \mathrm{g} / \mathrm{ml}$ Hoechst (cat. no. E607328; Sangon Biotech Co., Ltd.) was used for nuclear staining at $25^{\circ} \mathrm{C}$ for $30 \mathrm{~min}$. Images were obtained with Zeiss Axio Imager Z1 fluorescence microscope.

Senescence-associated $\beta$-galactosidase (SA- $\beta$-gal) staining. SA- $\beta$-gal was detected using the Senescence $\beta$-Galactosidase Staining kit (C0602; Beyotime) following the manufacturer's instructions: In brief, the cells were washed twice with PBS and then fixed with PBS containing $2 \%$ formaldehyde and $0.2 \%$ glutaraldehyde for $10 \mathrm{~min}$. The cells were then incubated at $37^{\circ} \mathrm{C}$ for $12 \mathrm{~h}$ with staining solution. After being washed twice with PBS, the SA- $\beta$-gal-positive cells were observed under an optical microscope (IX53; Olympus) and assessed using the ImageJ software.

Cell cycle analysis and Annexin V staining, and flow cytometry. For cell cycle analysis, the drug-treated cells at $80 \%$ confluence were harvested and fixed with $70 \%$ ethanol. For apoptosis analysis, the cells were cultured in attachment and then trypsinized and stained with PI/Annexin V (Apoptosis Detection kit; Vazyme Biotech Co., Ltd., Nanjing, China). Data were collected and analyzed on a BD FACSCalibur ${ }^{\mathrm{TM}}$ flow cytometer and using BD FACS Loader software (BD Biosciences).

Human colon cancer specimen collection. All human colon cancer and normal colon tissue specimens were collected from 
the Affiliated Hospital of Binzhou Medical College, Binzhou, China. Written consent was obtained from all patients and approval for the experiments was obtained from the Institute Research Ethics Committee of Binzhou Medical University. A total of 46 human lung tumor samples with matched pathologically normal lung samples were used for patient demographics and tumor characteristics and the association of the YAP level with the clinicopathological characteristics and 20 pairs of patient samples were used for immunohistochemical analysis.

Analysis of publicly available datasets. To examine the association between YAP expression level and the prognostic outcome of patients with NSCLC, Kaplan-Meier curves were used to estimate unadjusted overall survival (OS). The log-rank test was used to compare OS between groups. For patients with NSCLC with a low or high expression of YAP were generated using Kaplan-Meier Plotter (www.kmplot.com/analysis).

Spearman's rank correlation analysis. To examine the correlation between co-treatment with NCTD/DDP and the relative expression levels of E-cadherin or vimentin, we first performed a normality test, which indicated that there was a correlation between them and that the data were non-parametric. The correlation between the quantified levels of co-treatment with NCTD/DDP and the EMT marker protein levels, E-cadherin and vimentin was then assessed using Spearman's rank correlation coefficient based on the results of western blot analysis.In the graphs showing correlation analysis, the $\mathrm{x}$ axis represents the relative numbers of the increasing and decreasing ratio of the concentration for co-treatment with $\operatorname{NCTD}(8 \mu \mathrm{g} / \mathrm{ml})$ and DDP $(6 \mu \mathrm{g} / \mathrm{ml})$ (co-treatment with NCTD $4 \mu \mathrm{g} / \mathrm{ml}$ and DDP $3 \mu \mathrm{g} / \mathrm{ml}$ is defined as a value of 0.5 , co-treatment with NCTD $8 \mu \mathrm{g} / \mathrm{ml}$ and DDP $6 \mu \mathrm{g} / \mathrm{ml}$ defined is as a value of 1 and co-treatment with NCTD $16 \mu \mathrm{g} / \mathrm{ml}$ and DDP $12 \mu \mathrm{g} / \mathrm{ml}$ is defined as a value of 2 , etc.). The $y$ axis represents the relative protein levels of vimentin or E-cadherin.

Statistical analysis. Data were analyzed using GraphPad Prism 5 (GraphPad, La Jolla, CA, USA) and are presented as the means \pm SD. Two-tailed Student's t-tests were used to compare two groups and an ANOVA with a Tukey post hoc test was used to compare multiple groups. A P-value $<0.05$ was considered to indicate a statistically significant differen

\section{Results}

YAP is aberrantly activated in patient lung tumors. A total of 46 samples were obtained from patients who underwent a lung resection surgery at Affiliated Hospital of Binzhou Medical College (Binzhou, China) between January, 2010 and January, 2016. Each sample was examined, and the clinicopathological findings are summarized in Table I. To examine the endogenous mRNA and protein expression of YAP in human lung cancer cells, we performed RT-qPCR and western blot analysis, respectively. The YAP mRNA and protein levels were markedly increased in various human NSCLC (A549, H1299, Calu6 and H520) and lung giant cell carcinoma (95-D) cell lines compared with the normal human bronchial epithelial cells (Fig. 1A and B). In addition, the level of phosphorylated
Table I. Patient demographics and tumor characteristics and association of the YAP level with the clinicopathological characteristics of the lung cancer population.

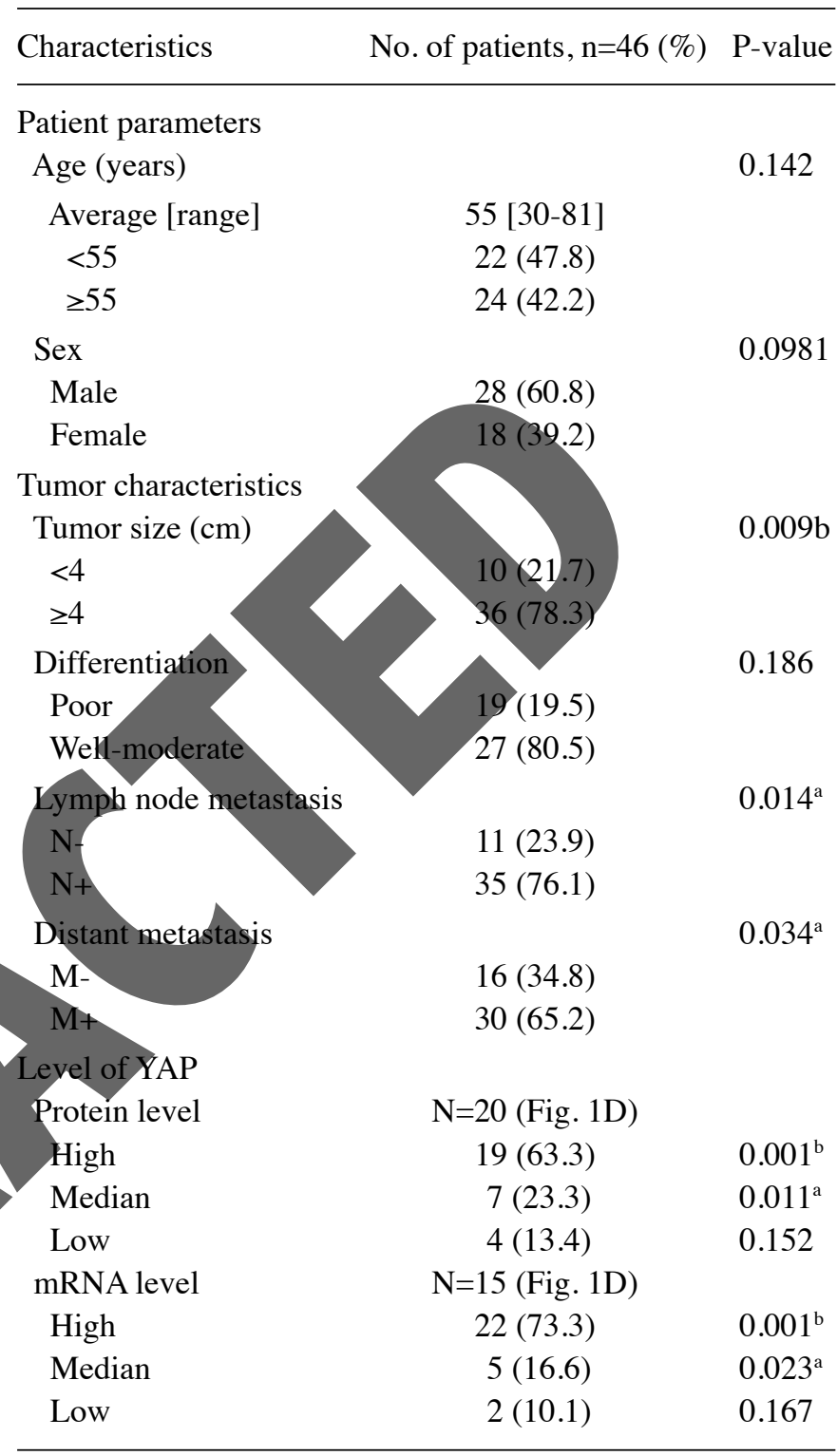

Differences between experimental groups were assessed by a Student's t-test or one-way analysis of variance. Data represent the means $\pm \mathrm{SD} .{ }^{\mathrm{a}} \mathrm{P}<0.05 ;{ }^{\mathrm{b}} \mathrm{P}<0.01$.

YAP (indicating cytoplasmic YAP localization) was lower in all of the lung cancer lines than in the normal cell line. Moreover, an MTT assay demonstrated that the lung cancer cells had a significantly higher proliferative capability than the normal cells (Fig. 1C). The staining of frozen tissue sections from patients with NSCLC for YAP confirmed the higher total expression and increased YAP accumulation in the lung tumor tissues compared to the adjacent normal lung tissues (Fig. 1D and Table I). Furthermore, western blot analysis and RT-qPCR of YAP expression revealed that both the protein and mRNA levels were markedly higher in the lung tumor tissues than in the adjacent normal lung tissues (Fig. 1E). Kaplan-Meier survival analysis also revealed 
$\mathbf{A}$
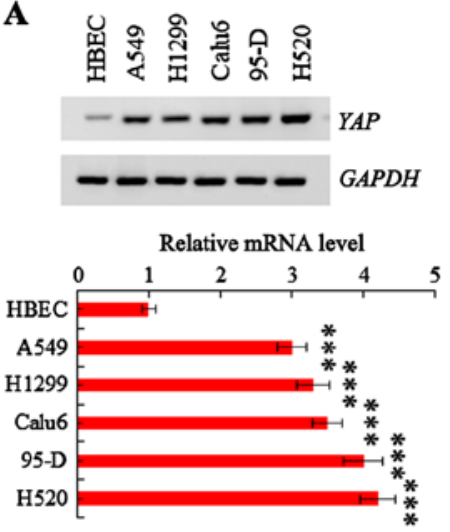

D

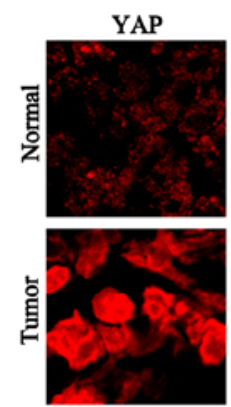

B

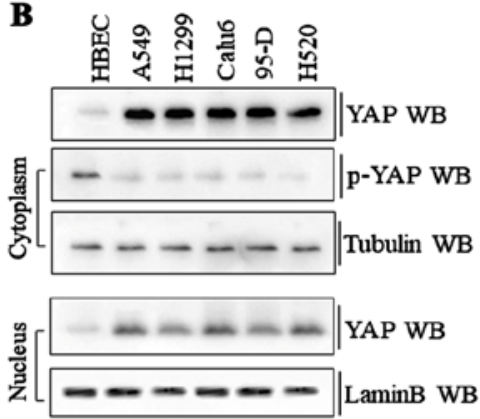

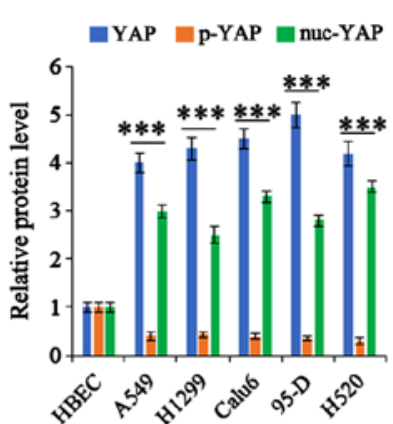

C

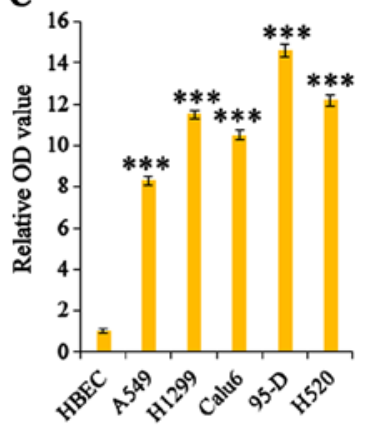

Figure 1. Aberrant activation of YAP in lung tumors from patients. (A and B) Gel-based qRT-PCR and western blot analysis densitometric quantification demonstrating elevated mRNA and protein expression levels of YAP in human non-small cell lung cancer (NSCLC) cells compared with the normal HBEC cells. (C) CCK-8 assay demonstrated that the NSCLC cells had a greater proliferative capability than the HBEC cells. (D) Immunohistochemical staining of YAP proteins showing increased total levels of YAP and that more YAP was accumulated in the nucleus in NSCLC samples compared with their normal adjacent lung tissues, while more YAP was localized in the cytoplasm of the normal adjacent lung tissues. (E) Relative protein and mRNA levels of YAP were assessed by western blot analysis and RT-qPCR in 20 pairs of NSCLC tissues and corresponding non-tumor tissues. (F) Kaplan-Meier overall survival (OS) curves of YAP ( $n=1926, p=1 E-09$ by log-rank test for significance). Results are presented as the means \pm SD, and the error bars represent the SD of 3 independent experiments. ${ }^{* * *} \mathrm{P}<0.001$ vs. normal cells or ti

a significantly decreased overall survival of patients with higher YAP levels ( $\mathrm{P}=0.004$, log-rank test; Fig. 1F).

YAP promotes NSCLC cell growth and invasion. We transfected the A549 NSCLC cells with a Myc-YAP plasmid and $Y A P$-specific siRNA to obtain stable cell lines in which YAP was overexpressed or knocked down, respectively; the transfection efficiency was verified by RT-PCR and western blot analysis (Fig. 2A). The cell limes were then used to explore the specific functions of YAP in cell proliferation and growth. MTT and colony formation assays revealed that cell proliferation and growth were substantially promoted and inhibited by the overexpression and knockdown of YAP, respectively (Fig. 2B and C). Moreover, SA- $\beta$-gal staining indicated that the stable expression of YAP reduced cell senescence, whereas its knockdown induced cell senescence (Fig. 2D). Scratch and Transwell assays revealed that YAP overexpression significantly increased cell invasion and migration compared with the controls, and the opposite effects were observed in the A549 cells in which YAP was knocked down (Fig. 2E and F). These data clearly demonstrate that YAP regulates NSCLC cell growth and invasion.

NCTD enhances DDP-induced tumor growth inhibition. Compared with the A549 and H1299 cells, the A549/DDP and H1299/DDP cells exhibited resistance to DDP and also exhibited higher mRNA and protein expression levels of YAP and its target genes, including $C Y R 61$ and $C T G F$, but lower levels of the inactivated form, $\mathrm{p}$-YAP, suggesting a possible role for YAP in inducing DDP resistance (Fig. 3A). A cell proliferation assay revealed that higher, but not lower concentrations of NCTD suppressed A549/DDP and H1299/DDP cell proliferation. However, treatment of the A549/DDP and H1299/DDP cells with various concentrations of DDP did not exert significant effects on cell proliferation (Fig. 3B). Based on time-response curves (Fig. 3C), $8 \mu \mathrm{g} / \mathrm{ml} \mathrm{NCTD} \mathrm{and} 6 \mu \mathrm{g} / \mathrm{ml}$ DDP (which had no significant effect on cell proliferation) were selected for use to examine the effects of NCTD/DDP co-treatment. The results of cell proliferation and growth assay indicated that A549/DDP and H1299/DDP cell viability was reduced to a greater extent with NCTD/DDP co-treatment than with the individual treatments (Fig. 3D). These data suggest that a low concentration of NCTD can markedly sensitize A549/DDP and H1299/DDP cells to the anti-proliferative effects of low-dose DDP.

NCTD enhances the DDP-induced suppressive effects on of YAP activity. Our previous study demonstrated that NCTD suppressed YAP expression in NSCLC (26). Moreover, YAP activity has been reported to mediate drug resistance $(27,28)$. To explore the effects of NCTD/DDP co-treatment on YAP, we used a luciferase reporter gene 
A

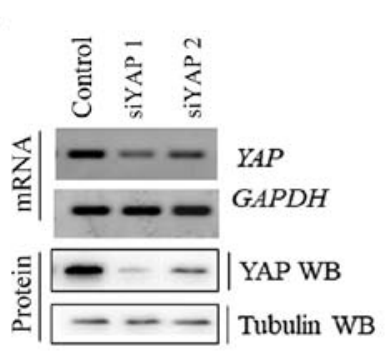

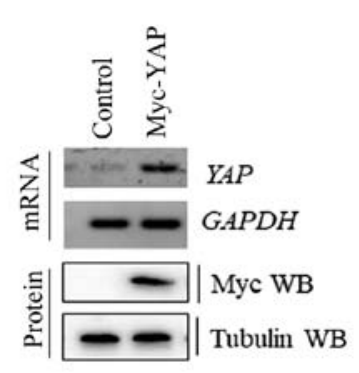

B

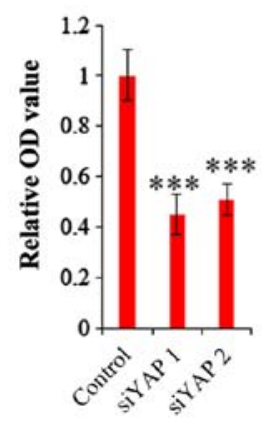

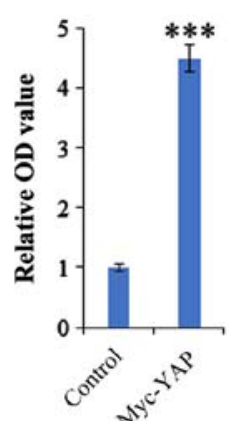

D
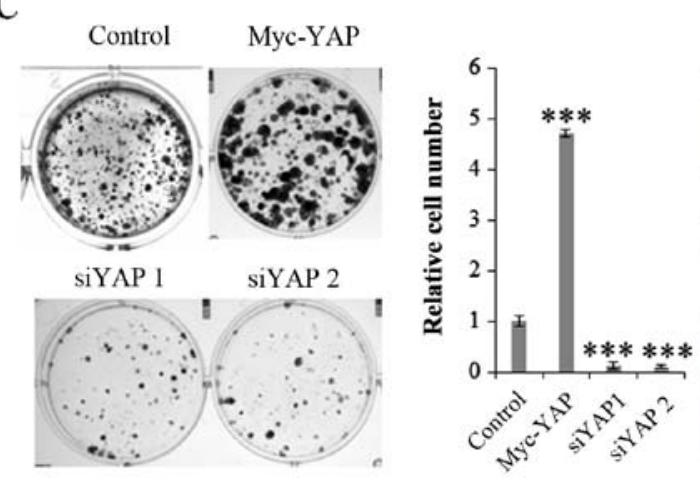

$$
\text { Control Myc-YAP }
$$

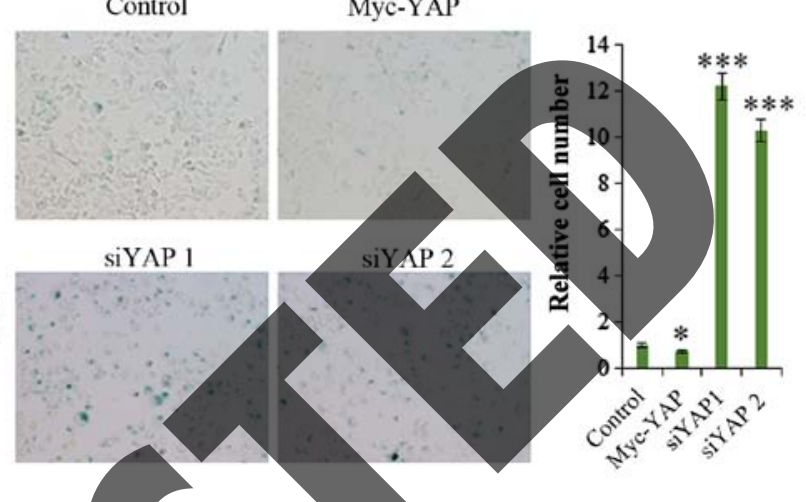

$\mathbf{E}$

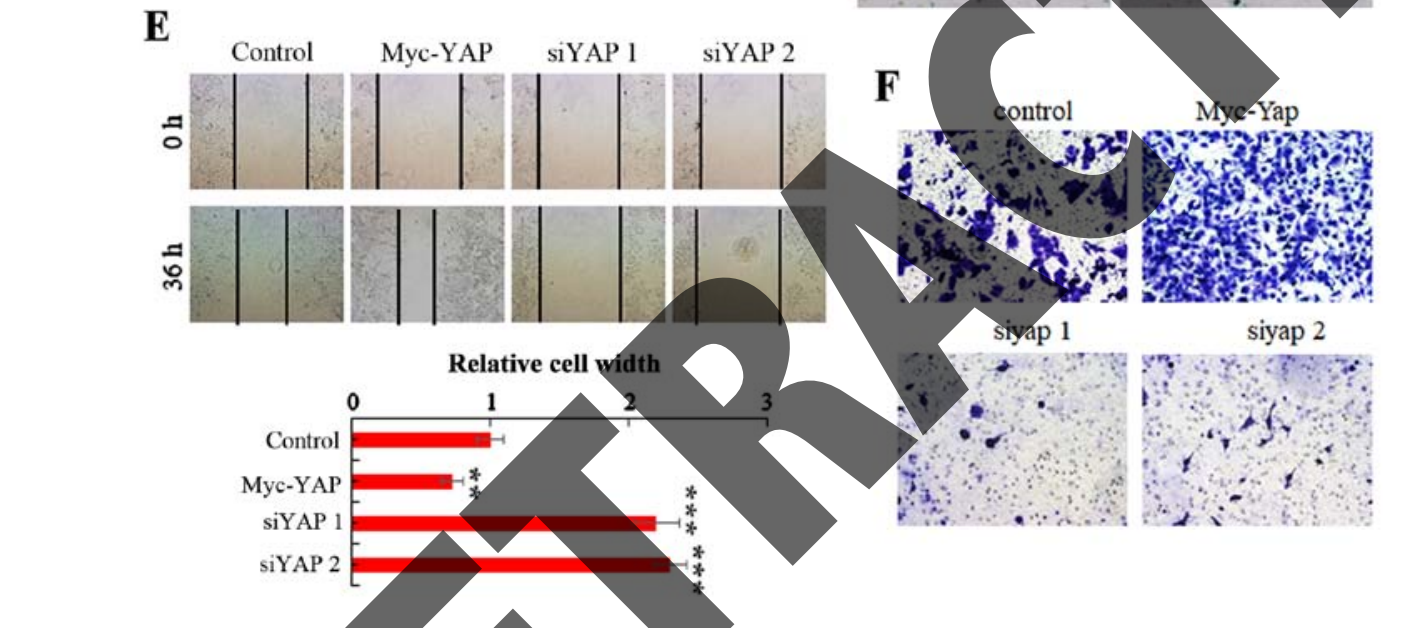

SiYAP 2

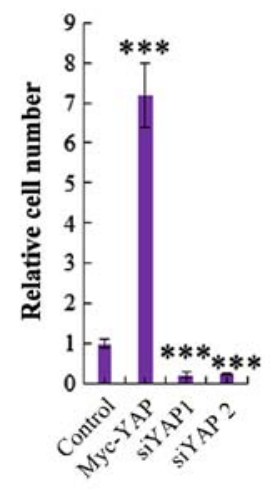

Figure 2. YAP regulates non-small cell lung eancer (NSCLC) cell growth and invasion. (A) RT-PCR and western blot analysis showing the mRNA and protein expression of YAP following transfection of A549 cells with siRNA against YAP or YAP overexpression vector. (B) CCK-8 assay demonstrating that the knockdown of YAP using siRNA or the stable overexpression of YAP significantly suppressed or promoted the proliferation of A549 cells, respectively. (C) Colony formation assay demonstrated that the colony formation density was significantly increased in cells stably expressing YAP and decreased in cells in which YAP was knocked down using the siRNA. (D) SA- $\beta$-Gal assay showing that the stable overexpression or knockdown of YAP using siRNA significantly blocked and promoted the cell senescence phenotype, respectively. (E) Scratch assay indicated that the stable overexpression of YAP or the knockdown of YAP using siRNA markedly increased or decreased the migration of A549 cells for $36 \mathrm{~h}$, respectively. (F) Transwell assay identified that the stable overexpression of YAP or the knockdown of YAP using siRNA significantly increased or decreased cell invasive growth compared with the A549 control cells. Results are presented as the means $\pm \mathrm{SD}$, and the error bars represent the $\mathrm{SD}$ of 3 independent experiments. ${ }^{*} \mathrm{P}<0.05 ;{ }^{* *} \mathrm{P}<0.01 ;{ }^{* * * *} \mathrm{P}<0.001$ vs. the control group.

assay. As shown in Fig. 4A, YAP promoter activity was markedly suppressed in the A549/DDP and H1299/DDP cells following NCTD/DDP co-treatment compared to the individual treatments. RT-qPCR and western blot analysis revealed that NCTD/DDP co-treatment decreased the mRNA and protein expression levels of YAP and its target genes, $C T G F$ and $C Y R 61$, in the A549/DDP cells, whereas it increased the level of inactive p-YAP (Fig. 4B and C). Immunofluorescence staining also demonstrated that the YAP protein level was significantly decreased in the A549/DDP cells following NCTD/DDP co-treatment compared to the individual treatments (Fig. 4D).
NCTD enhances DDP-mediated cell senescence and apoptosis. To further explore whether NCTD regulates the resistance of A549/DDP cells to DDP through the YAP pathway, we examined the cells for morphological changes. Indeed, NCTD/DDP co-treatment significantly affected cellular morphology, altering the cell shape from aflat to a more round one, compared to the individual treatments, which indicated that cells were in a state of poor survival (Fig. 5A). Moreover, NCTD/DDP co-treatment significantly decreased colony formation (Fig. 5B) and increased senescence (Fig. 5C) in the A549/DDP cells. We also confirmed that NCTD significantly enhanced the DDP-induced apoptosis of A549/DDP cells by 
A
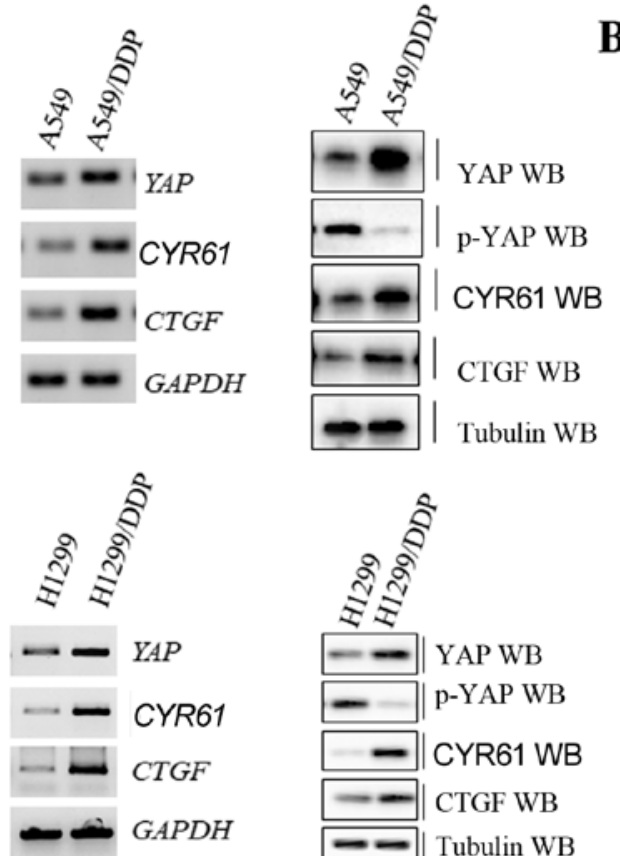

B
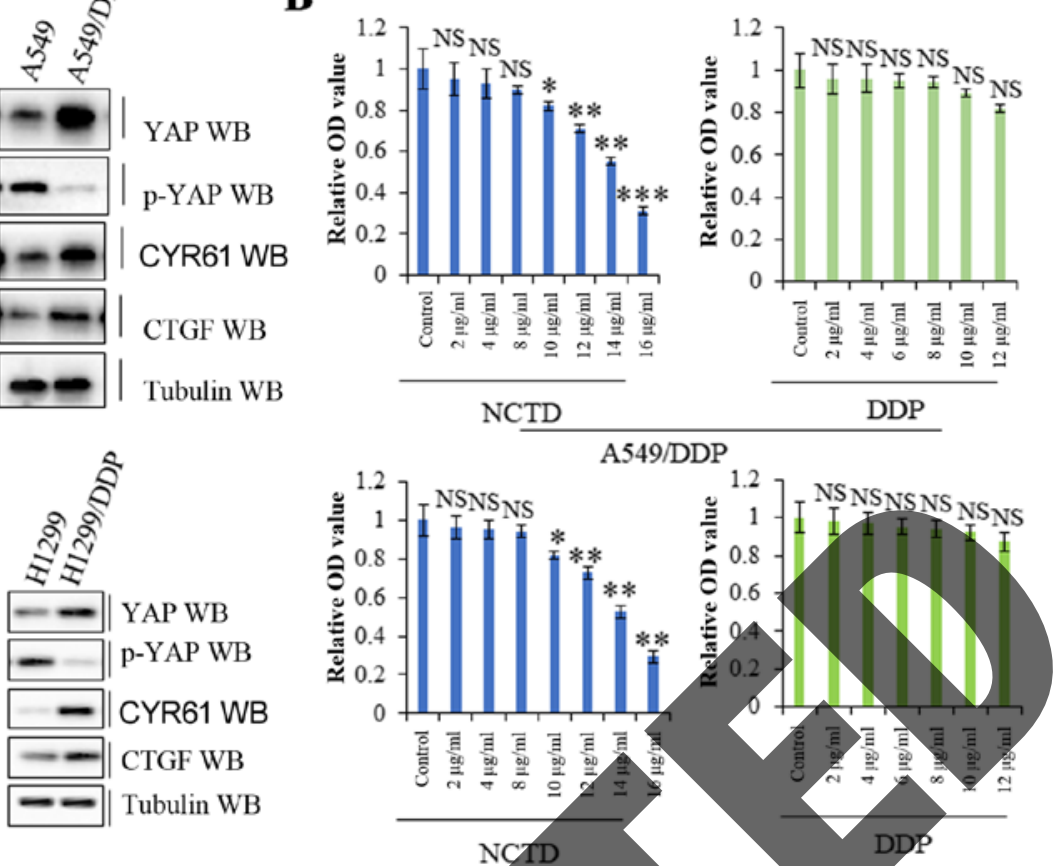

C
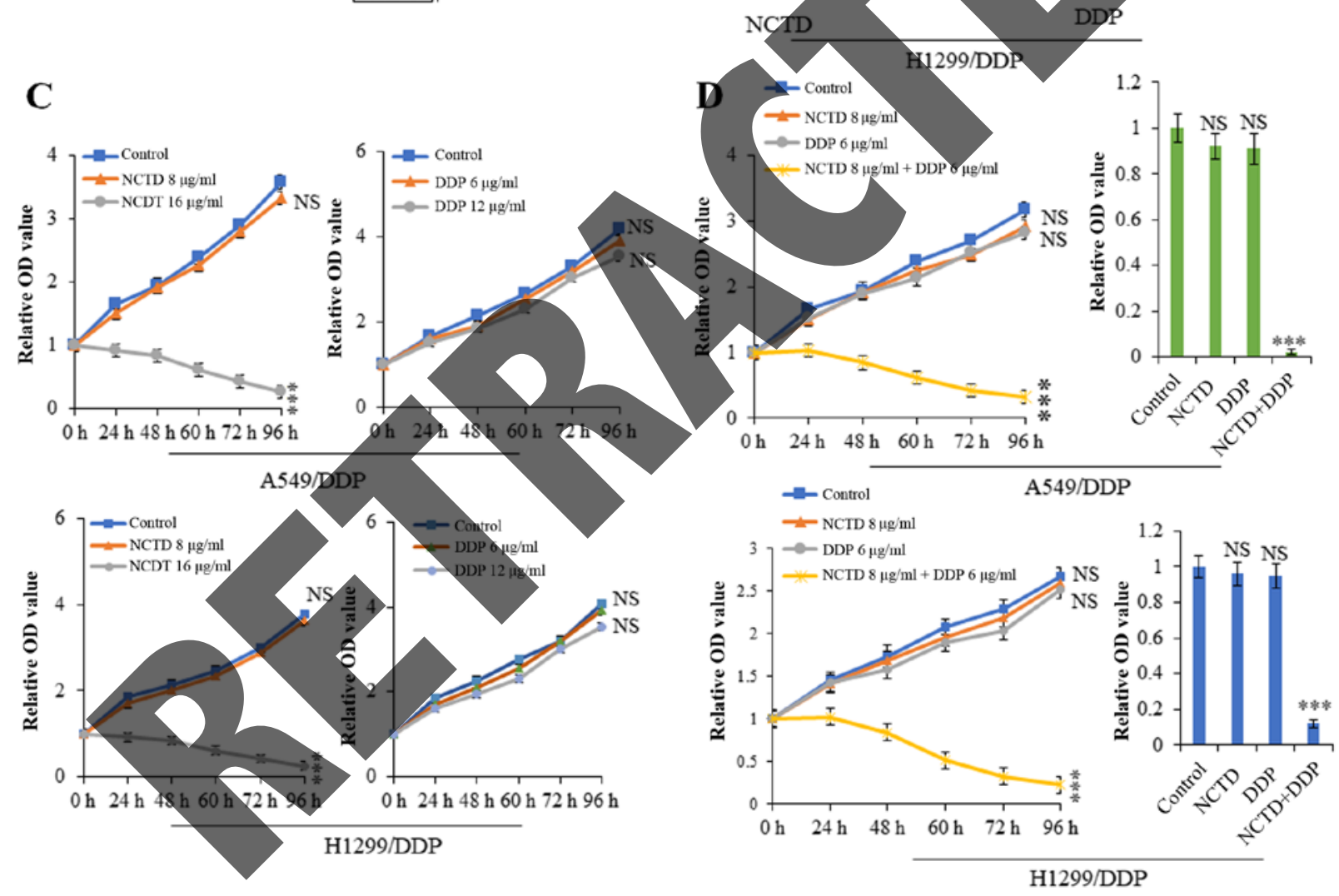

Figure 3. Norcantharidin (NCTD) sensitizes cells to cisplatin (DDP)-induced tumor growth inhibition. (A) RT-PCR and western blot analysis revealed that the mRNA and protein expression levels of YAP and its targets genes, including $C Y R 61$ and $C T G F$ were much higher in the A549/DDP and H1299/DDP cells than in the parent A549 and H1299 cells. (B and C) CCK-8 and MTT assay indicated that a higher, but not lower concentration of NCTD suppressed A549/DDP and H1299/DDP cell proliferation. However, the higher concentration of DDP still did not suppress A549/DDP cell proliferation. (D) Cellular growth and proliferation assay showing that a low dose of NCTD sensitized the A549/DDP and H1299/DDP cells to the anti-proliferative effects of low doses of DDP. Results are presented as the means $\pm \mathrm{SD}$, and the error bars represent the $\mathrm{SD}$ of 3 independent experiments. ${ }^{*} \mathrm{P}<0.05 ;{ }^{* *} \mathrm{P}<0.01{ }^{* * * *} \mathrm{P}<0.001$ vs. control group. NS, not significant.

detecting increased levels of activated caspase-3 by western blot analysis (Fig. 5D) and through Annexin V/propidium iodide apoptosis detection and flow cytometry (Fig. 5E and F) in the co-treated cells.
NCTD enhances the DDP-induced inhibitory effects on of YAP-mediated NSCLC cell invasiveness and EMT. Recent studies have demonstrated that drug resistance in human cancers is likely mediated by the EMT process though 
A
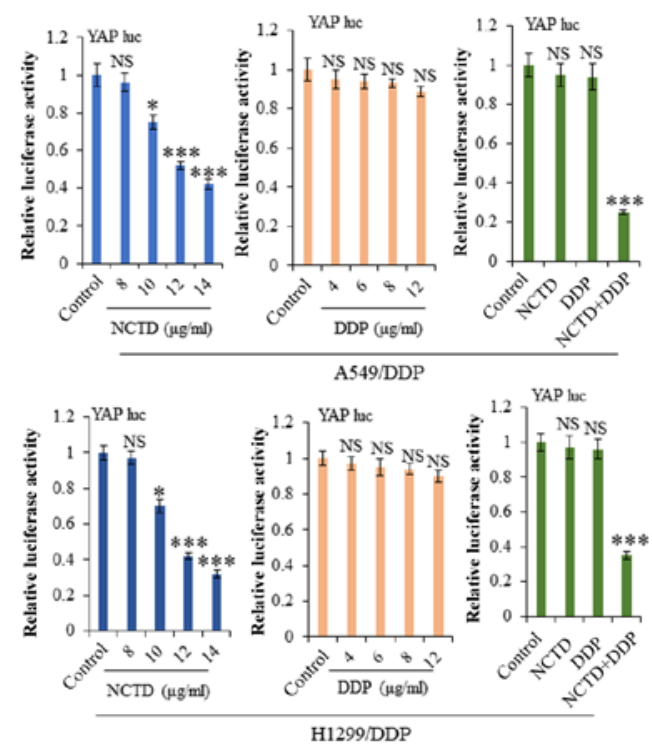

B
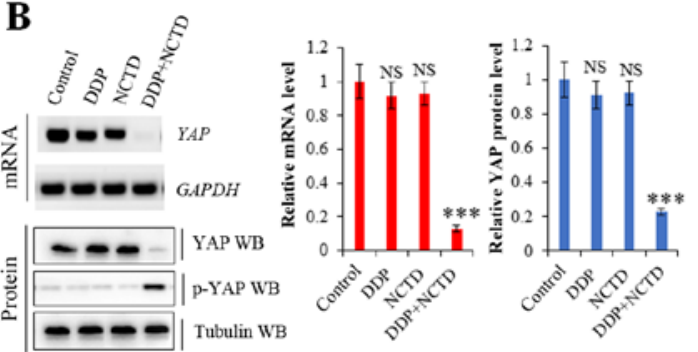

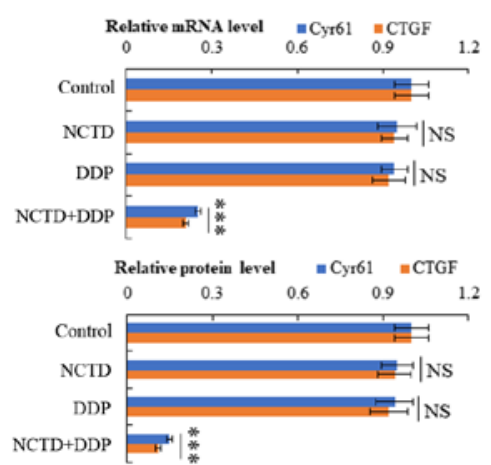

D
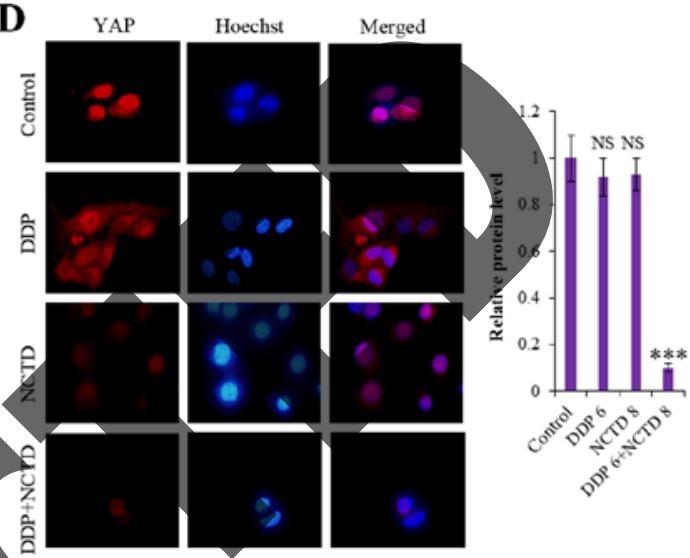

Figure 4. Norcantharidin (NCTD) sensitizes non-small cell lung cancer (NSCLC) cells to cisplatin (DDP) and suppresses the activity of YAP. (A) The effect of NCTD, DDP or co-treatment with both agents on the activities of YAR promoter was examined by luciferase reporter gene assays in A549/DDP and H1299/DDP cells. (B and C) RT-qPCR and western blot analysis demonstrating that NCTD enhanced the DDP-induced suppressive effects on the YAP, CTGF and CYR61 on mRNA and protein levels in the A549/DDP cells. (D) Immunofluorescence staining of YAP protein demonstrating that NCTD enhanced the DDP-induced suppressive effects on YAP expression in the A549/DDP cells. Results are presented as the means \pm SD, and the error bars represent the SD of 3 independent experiments. ${ }^{*} \mathrm{P}<0.05 ;{ }^{* * *} \mathrm{P}<0.001$ vs. the control group. NS, not significant.

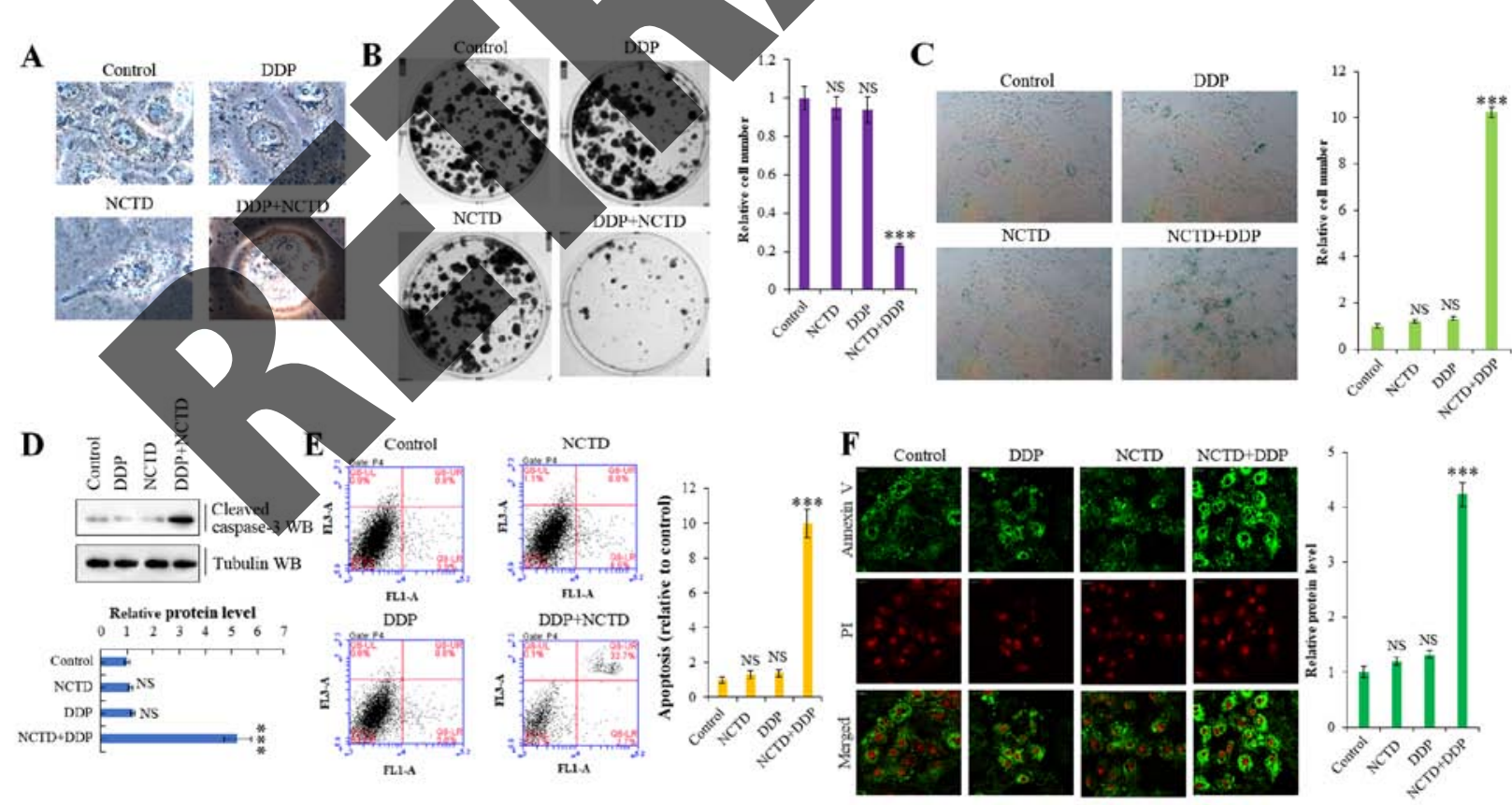

Figure 5. Norcantharidin (NCTD) sensitizes lung cancer cells to cisplatin (DDP)-induced senescence and apoptosis. (A) Phase contrast microscopy revealed that cellular morphology was significantly altered, from a flat to round shape, by co-treatment with NCTD and DDP in A549/DDP cells, which indicated that cells were in a state of poor survival. (B) Colony formation assay demonstrated that the colony formation density was significantly decreased following co-treatment with NCTD and DDP in A549/DDP cells. (C) SA- $\beta$-Gal assay showing that NCTD enhanced the DDP-induced cell senescence phenotype in A549/DDP cells. (D) Western blot analysis and densitometric quantification demonstrating that NCTD enhanced DDP-induced the expression of active caspase-3 on protein level in A549/DDP cells. (E and F) Flow cytometric and immunofluorescent staining assay demonstrating that NCTD enhanced the DDP-induced apoptosis of A549/DDP cells. Results are presented as the means \pm SD, and the error bars represent the SD of 3 independent experiments. ${ }^{* * * *} \mathrm{P}<0.001$ vs. control group. NS, not significant. 
A

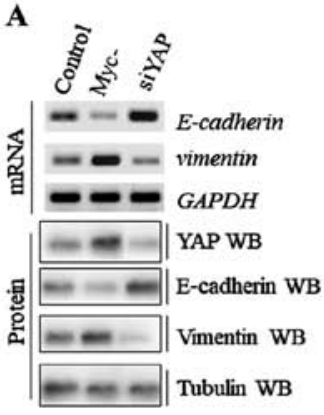

B

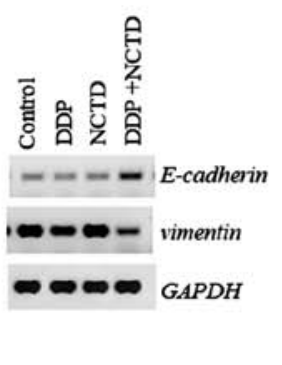

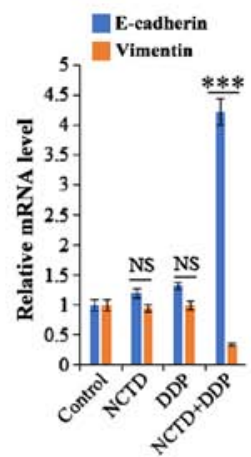

C

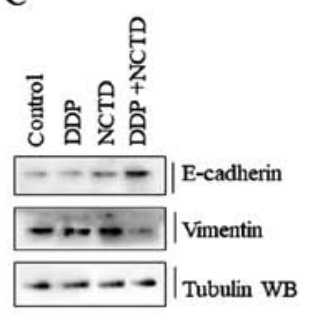

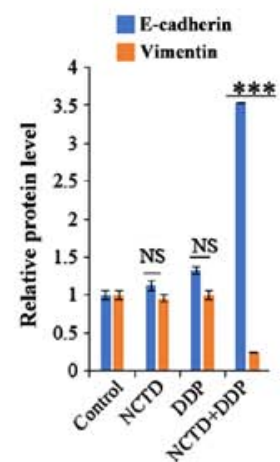

D
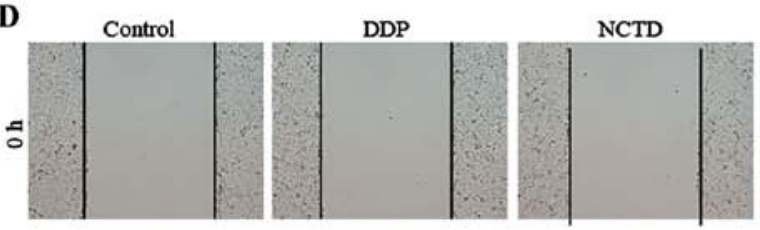

NCTD+DDP
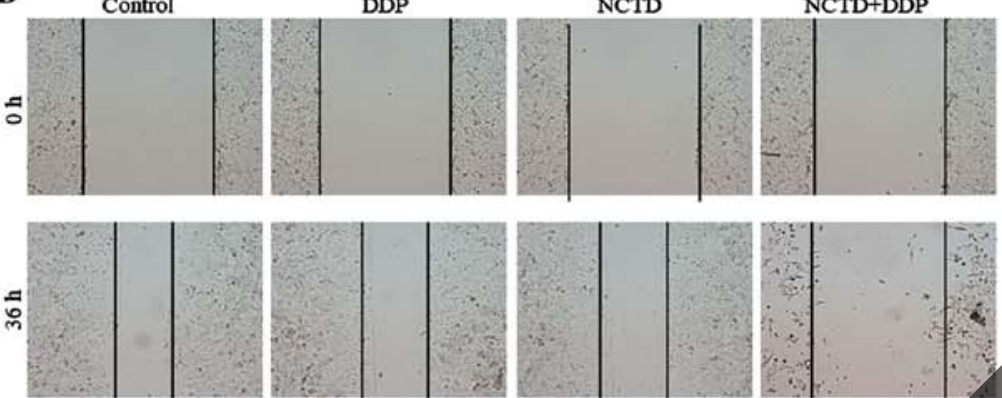

$\mathbf{E}$
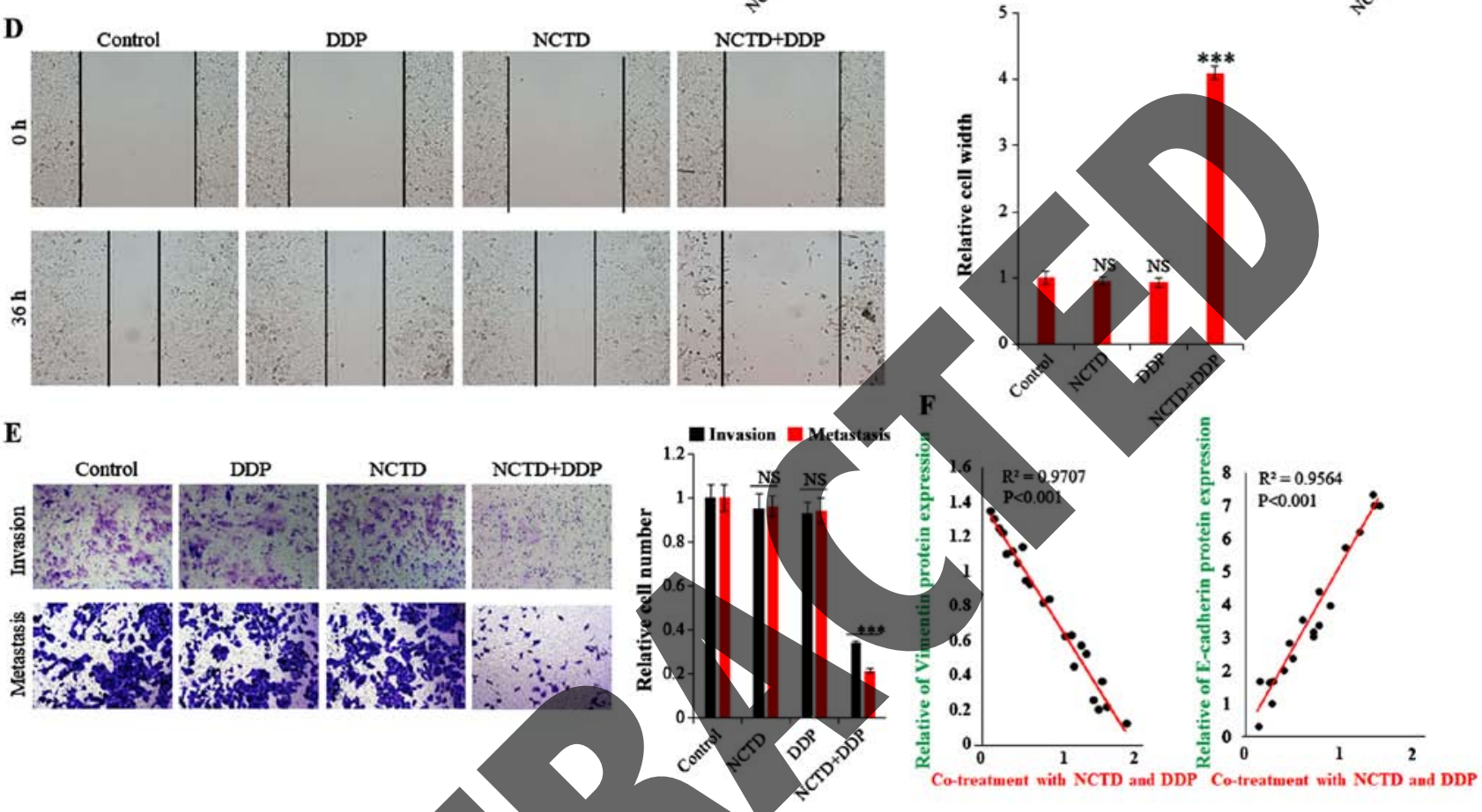

Figure 6. Norcantharidin (NCTD) sensitizes non-small cell lung cancer (NSCLC) cells to cisplatin (DDP) and suppresses YAP-mediated invasiveness and epithelial-mesenchymal transition (EMT). (A) RT-PCR and western blot analysis showing the mRNA and protein expression of E-cadherin and vimentin in A549/DDP cells transfected with siRNA or YAP overexpression vector. (B and C) RT-qPCR and western blot analysis and densitometric quantification demonstrating that NCTD enhanced the DDP-induced increase or decrease in the (B) mRNA and (C) protein level of E-cadherin or vimentin in A549/DDP cells. (D) Scratch assay showing that NCTD enhanced the DDP-induced decrease in the migration of A549/DDP cells at 36 h. (E) Transwell assay identified that NCTD enhanced the DDP-induced decrease in cellinvasiye growth and migration of the A549/DDP cells. (F) The correlation between the co-treatment with NCTD and DDP and EMT marker protein levels, E-cadherin and vimentin, was analyzed based on the results of western blot analysis, respectively. Results are presented as the means $\pm \mathrm{SD}$, and the error bars represent the $\mathrm{SD}$ of 3 independent experiments. ${ }^{* * * *} \mathrm{P}<0.001$ vs. the control group. NS, not significant.

the YAP pathway $(29,30)$. Thus, in this study, to examine the effects of NCTD and DDP on the EMT phenotype in A549/DDP cells, the mRNA and protein expression levels of EMT markers were evaluated. As shown in Fig. 6A, E-cadherin expression was enhanced and suppressed in the A549/DDP cells following YAP depletion and overexpression, respectively, while vimentin expression exhibited an opposite trend. On the whole, the data from this study indicate that YAP regulates EMT in A549/DDP cells (Fig. 6A). Moreover, E-cadherin expression was enhanced in the A549/DDP cells by NCTD/DDP co-treatment compared to that with the individual treatments, whereas vimentin expression was significantly decreased (Fig. 6B and C). Furthermore, scratch wound and Transwell assays revealed that co-treatment significantly decreased cell migration and invasion compared with the individual treatments (Fig. 6D and E). Spearman's rank correlation analysis also revealed significant positive correlations between NCTD/DDP co-treatment and EMT marker protein levels (E-cadherin), and negative correlations between NCTD/DDP co-treatment and vimentin, respectively (Fig. 6F). These data suggest that NCTD probably enhances the DDP-induced inhibitory effects on YAP-mediated NSCLC cell invasiveness and EMT, subverting DDP resistance.

\section{Discussion}

DDP, a non-specific cytotoxic antitumor drug targeting the cell cycle, is the common metal chemotherapeutic agent for the treatment of NSCLC $(5,6)$. However, patients with lung cancer treated with high concentrations of DDP are highly susceptible to cisplatin resistance and this eventually leads to a higher mortality rate. Thus, the identification of methods with which to reverse cisplatin resistance and enhance the sensitivity to DDP and relieve the damage of DDP to the body has become imperative for the clinical treatment of lung cancer. Our previous study demonstrated that NCTD not only inhibits 


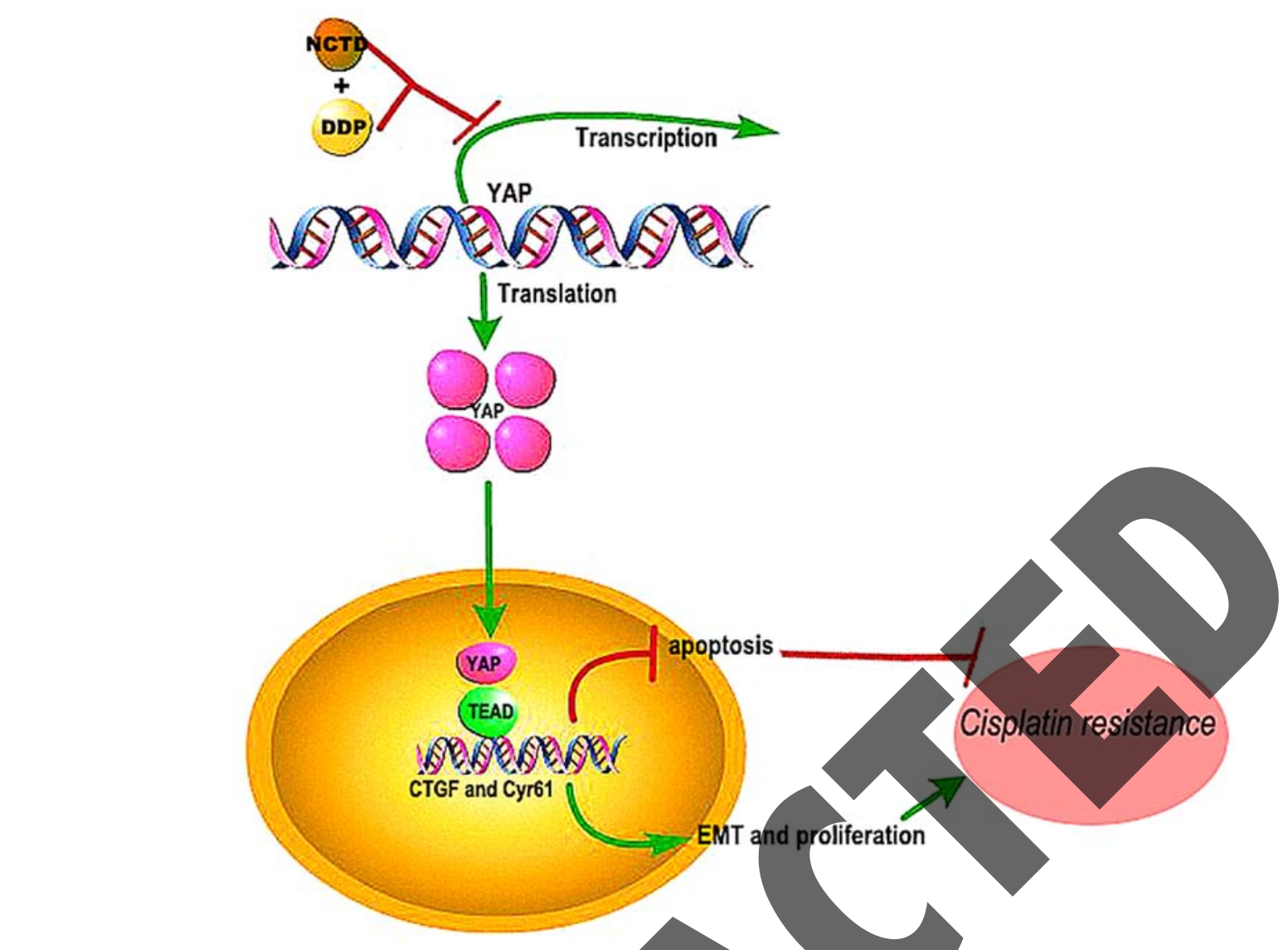

Figure 7. Schematic diagram of the mechanisms through which norcantharidin (NCTD) reverses cisplatin resistance and inhibits the epithelial mesenchymal transition of human cisplatin-resistant lung cancer cells via regulating the YAP pathway. NCTD may thus be an effective compound which may be used to reverse the resistance of human lung cancers to DDP by inhibiting YAP-induced anti-apoptotic effects, epithelial-mesenchymal transition (EMT), and proliferation and invasiveness.

the proliferation of varieties of cancer cell lines and in vivo xenografts, but also present no side-effects both in vitro and in vivo (26). Applying NCTD as a monotherapeutic drug in clinical trials substantially benefited patients with NSCLC (31). Moreover, NCTD as an efficient non-resistance therapeutic drug for patients with NSCLC can increase cellular apoptosis and senescence, and arrest tumor cell proliferation when used in conjunction with concentrations of DDP, reversing DDP resistance and enhancing the sensitivity to DDP. Thus, in this study, we extended our research and explored the mechanisms of co-treatment with NCTD and low concentrations of DDP, providing a novel strategy for the clinical treatment of patients with NSCLC.

Drug resistance remains a significant obstacle to the successful treatment of patients with lung cancer. Although our previous study demonstrated that NCTD suppresses YAP activity and disrupts YAP-mediated NSCLC progression and metastasis (26), the functions of YAP in chemoresistance have not been investigated in detail. In this study, we demonstrated that NCTD reversed the DDP-resistant status of A549/DDP cells, providing a potential strategy with which to prevent or delay the development of resistance during the treatment course. NCTD sensitized the resistant cells in several aspects, enhancing DDP-induced tumor growth inhibition, senescence, apoptosis, invasiveness, and inhibiting EMT, all of which were mediated by suppressing YAP expression at the transcriptional level.
YAP is a downstream effector of the YAP pathway, which plays an essential role in a variety of biological processes, such as proliferation, apoptosis, differentiation and development $(26,32,33)$. It has been suggested that YAP is linked to the development of resistance to anticancer drugs. YAP is overexpressed in resistant esophageal cancer tissues, and YAP activity has been shown to mediate resistance to 5 -fluorouracil and docetaxel in esophageal cancer cells (34). Similarly, the expression of YAP is enhanced in DDP-resistant ovarian cancer cells, and YAP knockdown inhibits the viability of resistant cells $(35,36)$. Therefore, YAP may be a potential target which may be used to reverse the drug resistance of human tumors, and the underlying mechanisms controlling this warrant further exploration.

Apoptosis plays an important role in the chemoresistance of NSCLC cells (37), and YAP is involved in this process by binding to the promoters of anti-apoptotic genes, including BCL2 like 1 (BCL2L1) and survivin, increasing their transcription (38). BCL2L1 has been shown to generate resistance to RAF and MEK inhibitors $(36,39)$, and survivin is a member of the inhibitor of apoptosis family, which inhibits cell apoptosis by suppressing caspase activity (40). Survivin inhibition has been suggested to reverse docetaxel resistance in gastric cancer cells (41), and the knockdown of survivin has been shown to desensitize H292 lung cancer cells to DDP therapy (42). Thus, YAP/TAZ activity may also promote drug 
resistance by inhibiting apoptosis. Consistently, our results revealed that NCTD/DDP co-treatment significantly increased apoptosis and the level of activated caspase- 3 compared to NCTD or DDP treatment alone. Moreover, co-treatment significantly decreased the expression levels of the YAP target genes $C T G F$ and $C Y R 61$.

EMT in tumor cells has also been suggested to play critical roles in drug resistance (29). In KRAS-dependent colon cancer cell lines and a mouse lung cancer model, YAP and the FOS protooncogene were shown to coordinately regulate a transcriptional program involved in EMT to rescue tumor cell viability upon KRAS suppression $(30,36)$. An elevated E-cadherin expression has been shown to increase the sensitivity of cells resistant to epithelial growth factor receptor kinase inhibitors, and resistant cells exhibited more mesenchymal-like properties (43). Thus, YAP may also contribute to drug resistance by affecting EMT induction. In accordance with this, our data demonstrated that NCTD/DDP co-treatment enhanced E-cadherin and reduced vimentin expression, and decreased the migration and invasion of DDP-resistant NSCLC cells.

Overall, the findings of this studys suggest that NCTD may be effective in reversing the resistance of human lung cancers to DDP by inhibiting YAP-induced anti-apoptotic effects, EMT, proliferation and invasiveness (Fig. 7). Although the mechanisms of these synergistic effects warrant further investigation, the combined treatment shows promise for improving the outcome and quality of life of patients with NSCLC

\section{Acknowledgements}

Not applicable.

\section{Funding}

This study was supported by Development Foundation of Yantai (grant no. 2015ZH082), the Natural Science Foundation of Shandong Province (grant nos. ZR2018QH004, ZR2016HB55, ZR2017PH067 and ZR2017MH125), and the Research Foundation of Binzhou Medical University (grant nos. BY2015KYQD29 and BY2015KJ14).

Availability of data and materials

The datasets used during the present study are available from the corresponding author upon reasonable request.

\section{Authors' contributions}

DJ and JG designed the experiments. DJ, YW, CS, YG, DW, JG performed the analyses and experiments. DJ and JG analyzed the data and compiled the figures. JG wrote the manuscript. All authors have read and approved the final manuscript.

\section{Ethics approval and consent to participate}

The experimental protocol was approved by the Research Ethics Committee of Binzhou Medical University (Binzhou,
China), (approval no. 2017-014-09 for the human tissues and 2017-05-12 for the mouse tissues). Written informed consent was obtained from all patients.

\section{Patient consent for publication}

Not applicable.

\section{Competing interests}

The authors declare that they have no competing interests.

\section{References}

1. Siegel R, Naishadham D and Jemal A: Cancer statistics, 2013. CA Cancer J Clin 63: 11-30

2. Ferlay J, Shin HR, Bray F, Forman D, Mathers C and Parkin DM: Estimates of worldwide burden of cancer in 2008: GLOBOCAN 2008. Int J Cancer 127: 2893-2917, 2010.

3. Ramalingam SS, Owønikoko TK and Khuri FR: Lung cancer: New biological insights and recent therapeutic advances. CA Cancer J Clin 61: 91-112, 2011.

4. Hurria A and Kris MG: Management of lung cancer in older adults. CA Cancer J Clin 53: 325-341, 2003.

5. Judson I and Kelland LR: New developments and approaches in the platinum arena. Drugs 59 (Suppl 4): S29-S38, 2000.

6. Oliver TG, Mercer KL, Sayles LC, Burke JR, Mendus D, Lovejoy KS, Cheng MH, Subramanian A, Mu D, Powers S, et al: Chronic cisplatin treatment promotes enhanced damage repair and tumor progression in a mouse model of lung cancer. Genes Dev 24: 837, 852, 2010.

7. Valle J, Wasan H, Palmer DH, Cunningham D, Anthoney A, Maraveyas A, Madhusudan S, Iveson T, Hughes $S$, Pereira SP, et al: Cisplatin plus gemcitabine versus gemcitabine for biliary tract cancer. New Engl J Med 362: 1273-1281, 2010.

Shen DW, Pouliot LM, Hall MD and Gottesman MM: Cisplatin resistance: A cellular self-defense mechanism resulting from multiple epigenetic and genetic changes. Pharmacol Rev 64: 706-721, 2012.

9. Rosell R, Lord RV, Taron M and Reguart N: DNA repair and cisplatin resistance in non-small-cell lung cancer. Lung Cancer 38: 217-227, 2002.

10. Wei F, Jiang X, Gao HY and Gao SH: Liquiritin induces apoptosis and autophagy in cisplatin (DDP)-resistant gastric cancer cells in vitro and xenograft nude mice in vivo. Int J Oncol 51: 1383-1394, 2017.

11. Chaib I, Karachaliou N, Pilotto S, Codony Servat J, Cai X, Li X, Drozdowskyj A, Servat CC, Yang J, Hu C, et al: Co-activation of STAT3 and YES-associated protein 1 (YAP1) pathway in EGFR-mutant NSCLC. J Natl Cancer Inst 109, 2017.

12. Zhang W, Gao Y, Li F, Tong X, Ren Y, Han X, Yao S, Long F, Yang $\mathrm{Z}$, Fan $\mathrm{H}$, et al: YAP promotes malignant progression of $L k b l$-deficient lung adenocarcinoma through downstream regulation of survivin. Cancer Res 75: 4450-4457, 2015.

13. Karachaliou N, Chaib I, Pilotto S, Codony J, Cai X, Li X, Marin S, Zhou C, Cao P and Rosell R: 76P An innovative co-targeting of signal transducer and activator of transcription 3 (STAT3) and Src-YAP pathways in EGFR mutant non-small cell lung cancer (NSCLC). J Thorac Oncol 11 (Suppl 4): S87-S88, 2016.

14. Pan D: Hippo signaling in organ size control. Genes Dev 21: 886-897, 2007.

15. Zanconato F, Cordenonsi M and Piccolo S: YAP/TAZ at the roots of cancer. Cancer Cell 29: 783-803, 2016.

16. Guo L and Teng L: YAP/TAZ for cancer therapy: Opportunities and challenges (Review). Int J Oncol 46: 1444-1452, 2015.

17. Morikawa Y, Heallen T, Each JL, Xiao Y and Martin JF: Dystrophin-glycoprotein complex sequesters Yap to inhibit cardiomyocyte proliferation. Nature 547: 227-231, 2017.

18. Britschgi A, Duss S, Kim S, Couto JP, Brinkhaus H, Koren S, De Silva D, Mertz KD, Kaup D, Varga Z, et al: The Hippo kinases LATS1 and 2 control human breast cell fate via crosstalk with ER $\alpha$. Nature 541: 541-545, 2017.

19. Gregorieff A, Liu Y, Inanlou MR, Khomchuk Y and Wrana JL: Yap-dependent reprogramming of $\mathrm{Lgr}^{+}$stem cells drives intestinal regeneration and cancer. Nature 526: 715-718, 2015. 
20. Park HW, Kim YC, Yu B, Moroishi T, Mo JS, Plouffe SW, Meng ZP, Lin KC, Yu FX, Alexander CM, et al: Alternative Wnt signaling activates YAP/TAZ. Cell 162: 780-794, 2015.

21. Wang GS: Medical uses of mylabris in ancient China and recent studies. J Ethnopharmacol 26: 147-162, 1989.

22. Yu CC, Ko FY, Yu CS, Lin CC, Huang YP, Yang JS, Lin JP and Chung JG: Norcantharidin triggers cell death and DNA damage through S-phase arrest and ROS-modulated apoptotic pathways in TSGH 8301 human urinary bladder carcinoma cells. Int J Oncol 41: 1050-1060, 2012.

23. Zhang JT, Fan YZ, Chen CQ, Zhao ZM and Sun W: Norcantharidin: A potential antiangiogenic agent for gallbladder cancers in vitro and in vivo. Int J Oncol 40: 1501-1514, 2012.

24. Chen QY, Jiao DM, Wang J, Hu H, Tang X, Chen J, Mou H and $\mathrm{Lu} \mathrm{W:} \mathrm{miR-206}$ regulates cisplatin resistance and EMT in human lung adenocarcinoma cells partly by targeting MET. Oncotarget 7: 24510-24526, 2016.

25. Livak KJ and Schmittgen TD: Analysis of relative gene expres-

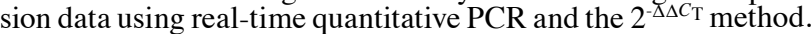
Methods 25: 402-408, 2001.

26. Guo J, Wu Y, Yang L, Du J, Gong K, Chen W, Dai J, Li X and Xi S: Repression of YAP by NCTD disrupts NSCLC progression. Oncotarget 8: 2307-2319, 2017.

27. Li K, Guo J, Wu Y, Jin D, Jiang H, Liu C and Qin C: Suppression of YAP by DDP disrupts colon tumor progression. Oncol Rep 39: 2114-2126, 2018.

28. Lee TF, Tseng YC, Nguyen PA, Li YC, Ho CC and Wu CW: Enhanced YAP expression leads to EGFR TKI resistance in lung adenocarcinomas. Sci Rep 8: 271, 2017.

29. Singh A and Settleman J: EMT, cancer stem cells and drug resistance: An emerging axis of evil in the war on cancer. Oncogene 29: 4741-4751, 2010.

30. Shao DD, Xue W, Krall EB, Bhutkar A, Piccioni F, Wang X, Schinzel AC, Sood S, Rosenbluh J, Kim JW, et al: KRAS and YAP1 converge to regulate EMT and tumor survival. Cell 158 : 171-184, 2014

31. Hsieh CH, Chao KS, Liao HF and Chen YJ: Norcantharidin, derivative of cantharidin, for cancer stem cells. Evid Based Complement Alternat Med 2013: 838651, 2013.

32. Bae JS, Kim SM and LeeH: The Hippo signaling pathway provide novel anti-cancer drug targets. Oncotarget 8: 16084-16098, 2017

33. Wang Y, Ding W, Chen C, Niu Z, Pan M and Zhang H: Ro of Hippo signaling in lung cancer. Indian J Cancer 52 (Suppl 1) e1-e5, 2015.

34. Song S, Honjo S, Jin J, Chang SS, Scott AW, Chen Q, KalhorN, Correa AM, Hofstetter WL, Albarracin CT, et al: The Hippo coactivator YAP1 mediates EGFR overexpression and confer chemoresistance in esophageal cancer. Clin Cancer Res 21 . 2580-2590, 2015.
35. Xiao L, Shi XY, Zhang Y, Zhu Y, Zhu L, Tian W, Zhu BK and Wei ZL: YAP induces cisplatin resistance through activation of autophagy in human ovarian carcinoma cells. Onco Targets Ther 9: 1105-1114, 2016.

36. Kim MH and Kim J: Role of YAP/TAZ transcriptional regulators in resistance to anti-cancer therapies. Cell Mol Life Sci 74: 1457-1474, 2017.

37. Ye LY, Hu S, Xu HE, Xu RR, Kong H, Zeng XN, Xie WP and Wang H: The effect of tetrandrine combined with cisplatin on proliferation and apoptosis of A549/DDP cells and A549 cells. Cancer Cell Int 17: 40, 2017.

38. Rosenbluh J, Nijhawan D, Cox AG, Li X, Neal JT, Schafer EJ, Zack TI, Wang X, Tsherniak A, Schinzel AC, et al: $\beta$-Catenin-driven cancers require a YAP1 transcriptional complex for survival and tumorigenesis. Cell 151: 1457-1473, 2012.

39. Lin L, Sabnis AJ, Chan E, Olivas V, Cade L, Pazarentzos E, Asthana S, Neel D, Yan JJ, La X, et al: The Hippo effector YAP promotes resistance to RAF- and MEK-targeted cancer therapies. Nat Genet 47: 250-256, 2015.

40. Zheng HC: The molectular mechanisms of chemoresistance in cancers. Oncotarget 8: 59950-59964, 2017.

41. Wang T, Wei J, Qian X, Ding Y, Yu L and Liu B: Gambogic acid, a potent inhibitor of survivin, reverses docetaxel resistance in gastric cancer cells. Cancer Lett 262: 214-222, 2008.

42. Tian A, Wilson GS, Lie S, Wu G, Hu Z, Hebbard L, Duan W, George J and Qiao L: Synergistic effects of IAP inhibitor LCL161 and paclitaxel on hepatocellular carcinoma cells. Cancer Lett 351: 232-241, 2014.

43. Witta SE, Gemmill RM, Hirsch FR, Coldren CD, Hedman K, Ravdel L, Helfrich B, Dziadziuszko R, Chan DC, Sugita M, et al: Restoring E-cadherin expression increases sensitivity to epidermal gtowth factor receptor inhibitors in lung cancer cell lines. Cancer Res 66: 944-950, 2006.

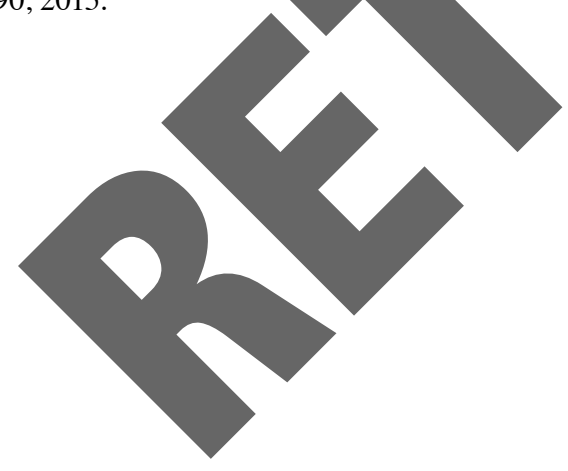

This work is licensed under a Creative Commons Attribution-NonCommercial-NoDerivatives 4.0 International (CC BY-NC-ND 4.0) License. 